\title{
A systematic review of Gamma-aminobutyric Acid Receptor Type B autoimmunity
}

\author{
Jake H. McKay ${ }^{1}$, Elliot L. Dimberg ${ }^{1}$, Alfonso S. Lopez Chiriboga ${ }^{2}$ \\ ${ }^{1}$ Mayo Clinic, Jacksonville, Florida, USA \\ ${ }^{2}$ Mayo Clinic Minnesota, Rochester, Minnesota, USA
}

\section{ABSTRACT}

Objective. To review the available research to describe the clinical characteristics and neoplastic associations of patients with gamma-aminobutyric acid receptor type B (GABAB-R) autoantibodies.

Methods. Literature was reviewed on PubMed, Mendeley literature search, and the American Academy of Neurology database for articles published from June 2008 to October of 2018 using a variety of key words. These key words include:,"gamma-aminobutyric acid seizures,",gamma-aminobutyric acid limbic encephalitis",, GABA(B) receptor antibodies,", autoimmune encephalitis,",autoimmune epilepsy,","GABA(B) encephalitis, , and "GABA paraneoplastic."With the results, the papers were reviewed in a systematic manner.

Results. A total of 10 studies were reviewed. A summary of the demographic, clinical, and serological findings of the cases detailed in the literature are provided. An additional illustrative case is described. In total, 94 patients were reviewed.

Conclusions. GABAB-R autoimmune disease is characterized by refractory seizures or status epilepticus and frequent association with small cell lung cancer. Additionally, a substantial minority of patients have non-inflammatory CSF.

Key words: Gamma-aminobutyric acid seizures, gamma-aminobutyric acid receptor type B, GABA(B) receptor antibodies, autoimmune encephalitis, autoimmune epilepsy, GABA-B encephalitis, GABA limbic encephalitis, GABA paraneoplastic (Neurol Neurochir Pol 2019; 53 (1): 1-7)

\section{Introduction}

The field of autoimmune neurology has evolved rapidly in the years following the discovery of $\mathrm{N}$-methyl-D-aspartate receptor (NMDA-R) encephalitis in 2007 [1]. As more neural autoantibodies have been discovered, cases of encephalitis previously presumed to be viral or idiopathic have been determined to be autoimmune in aetiology [2]. Gamma-aminobutyric acid receptor type $B\left(\mathrm{GABA}_{B}-\mathrm{R}\right)$ antibody autoimmune encephalitis, first described in the literature in 2010 by Lancaster et al. [3], has been followed by several additional case series and retrospective studies $[4,5]$.

As more clinical cases have been reported, the profile of the clinical, radiological, and serological characteristics of $\mathrm{GABA}_{\mathrm{B}}-\mathrm{R}$ autoimmunity has continued to expand. While symptoms of limbic encephalitis (seizures, confusion, and memory loss) and frequent association with small cell lung cancer (SCLC) were characteristics originally proposed $[3,5]$ memory loss, and confusion, compatible with limbic encephalitis (LE, additional associated features have become apparent, including: status epilepticus, ataxia, epileptiform electroencephalogram (EEG) findings, and sometimes benign cerebrospinal fluid (CSF) studies [5-7]. Given the neoplastic associations of $\mathrm{GABA}_{B}-\mathrm{R}$ antibody encephalitis, and its tendency to respond to immunosuppressive treatment [5] prompt recognition of the disorder is crucial as this can improve oncologic and neurologic outcomes.

$\mathrm{GABA}_{\mathrm{B}}-\mathrm{R}$ is a G-protein coupled receptor known to play a role in the suppression of neural or seizure activity [8] and is widely distributed in the hippocampus, thalamus and cerebellum [9]. GABA receptor is composed of $\mathrm{GABA}_{\mathrm{B} 1}$ and $\mathrm{GABA}_{\mathrm{B} 2}$ subunits. Binding of GABA to the $\mathrm{GABA}_{\mathrm{B} 1}$ subunit results in conformational changes, causing inhibition of neuronal firing activity principally by inhibiting presynaptic calcium channels [8]. There is evidence that a lack of normal $\mathrm{GABA}_{\mathrm{B}}-\mathrm{R}$ structure and function can lead to spontaneous seizures [10]. Autoantibodies in the CSF of anti-GABA receptor encephalitis patients prevent activation of GABA receptors in 
vitro by blocking receptor function without altering receptor surface density [11].

In this study, we review the current literature relating to $\mathrm{GABA}_{\mathrm{B}}-\mathrm{R}$ autoimmunity, describing the clinical features, laboratory evaluation, oncologic associations, and treatment response of the disorder in a comprehensive manner. We will also provide an illustrative new clinical case of $G_{A B A}-R$ antibody encephalitis on which the diagnosis was obtained postmortem, as testing was unavailable at the time of presentation.

\section{State of the art}

We identified a total of 94 confirmed cases of $\mathrm{GABA}_{B}$ -R encephalitis, including case series from Lancaster et al. [3], Boronat et al. [4], Höftberger et al. [5], Guan et al. [6], Onugoren et al. [7], Kim et al. [12], and Chen et al. [13]. Additionally, several case reports, including one of our own, were included in the analysis [14-16]. All studies were retrospective. The average patient age was 59.6 years, with a range of 16 to 84 years. We only included patients of 16 years or older, given the frequently distinct paraneoplastic associations in paediatric patients [17]. However, we do recognise that, in the paediatric literature, $\mathrm{GABA}_{\mathrm{B}}-\mathrm{R}$ encephalitis has been rarely reported, including a patient as young as three years old [18]. The male to female ratio was 59:35, with males comprising $62.8 \%$ (59/94) of the total number of cases. While most studies focus on Caucasian patients, the studies by Guan, Kim, and Chen have described the disorder in an East Asian population $(\mathrm{n}=34)$.

Patients most commonly presented with seizures, which were diagnosed in $84.0 \%$ (79/94) of cases on initial evaluation, with status epilepticus in $9.6 \%$ (9/94). Limbic symptoms characterised by confusion, disorientation, or behavioural change were seen in $67.1 \%(51 / 76)$ of patients at the time of presentation, whereas gait ataxia and gait instability were seen in $11.7 \%(11 / 94)$. The presenting symptoms are summarised in Table 1. Of all patients, $14.9 \%$ (14/94) ultimately developed coma or required an Intensive Care Unit (ICU) level of care for airway support or ventilator management. An atypical case with coexistent anti-Hu and anti-CV2 autoantibodies was described with vertigo, hiccups, and vomiting, and was ultimately found to have brainstem involvement [14]. A summary of the symptoms encountered throughout the course of illness is presented in Table 2. The mean follow-up for cases with clearly defined data was 10.4 months, with a range from hospital discharge to 90 months $(\mathrm{n}=66)$.

\section{CSF findings}

Of the cases with available CSF data, 59.3\% (51/86) had CSF pleocytosis, and $43.9 \%(29 / 66)$ had elevated protein in CSF. Testing for $\mathrm{GABA}_{B}-\mathrm{R}$ autoantibodies was more sensitive in CSF than serum, with autoantibodies for $\mathrm{GABA}_{B}$ - R identified in $98.3 \%(71 / 72)$ of subject CSF and $88.1 \%$ (69/77) of serum samples.

\section{Imaging findings}

Magnetic resonance imaging (MRI) brain findings appeared to have a strong predilection for the temporal lobes, with $54.8 \%$ (51/94) of cases having either unilateral or bilateral temporal lobe hyperintensity on MRI brain T2. Of patients with temporal lobe hyperintensity on brain MR T2 imaging, bilateral temporal lobe hyperintensity occurred in 59.5\% $(25 / 42)$ of cases with available data.

Table 1. Summary of the most commonly encountered presenting symptoms

\begin{tabular}{|c|c|c|c|c|c|}
\hline Study & Subjects & Seizures & Status Epilepticus & Ataxia & Confusion/Behavioural Change \\
\hline Lancaster [3] & 15 & 13 & 3 & 0 & 2 \\
\hline Boronat [4] & 11 & 9 & 1 & 1 & 9 \\
\hline Höftberger [5] & 20 & 18 & 0 & 1 & 17 \\
\hline Guan [6] & 18 & 16 & 0 & 2 & ND \\
\hline Onugoren [7] & 10 & 8 & 2 & 3 & 8 \\
\hline $\operatorname{Kim}[12]$ & 5 & 3 & 0 & 0 & 5 \\
\hline Chen [13] & 11 & 11 & 3 & 1 & 9 \\
\hline Alexopoulos [14] & 1 & 0 & 0 & 0 & 0 \\
\hline Jarius [15] & 1 & 0 & 0 & 1 & 0 \\
\hline Mimbrera [16] & 1 & 0 & 0 & 1 & 0 \\
\hline Illustrative case & 1 & 1 & 0 & 1 & 1 \\
\hline Total: & 94 & 79 & 9 & 11 & $51(n=76)$ \\
\hline Percentage: & & $84.0 \%$ & $9.6 \%$ & $11.7 \%$ & $67.1 \%$ \\
\hline
\end{tabular}

ND - no data 
Table 2. Summary of the symptoms encountered during illness

\begin{tabular}{|c|c|c|c|c|c|c|c|c|c|}
\hline Study & Subjects & Seizure & $\begin{array}{c}\text { GTC } \\
\text { Seizure }\end{array}$ & $\begin{array}{c}\text { Status } \\
\text { Epilepticus }\end{array}$ & $\begin{array}{c}\text { Memory } \\
\text { Impairment }\end{array}$ & Confusion & $\begin{array}{c}\text { Agitation/ } \\
\text { Behavioural } \\
\text { change }\end{array}$ & $\begin{array}{l}\text { Coma/ } \\
\text { ICU }\end{array}$ & Ataxia \\
\hline Lancaster [3] & 15 & 15 & 8 & 3 & 15 & 15 & 5 & 4 & 1 \\
\hline Boronat [4] & 11 & 8 & ND & 1 & 6 & 4 & 4 & ND & 1 \\
\hline Höftberger [5] & 20 & 20 & ND & 1 & 20 & 20 & ND & 1 & 2 \\
\hline Guan [6] & 18 & 17 & 17 & 4 & 12 & ND & 11 & 4 & 3 \\
\hline Onugoren [7] & 10 & 8 & 8 & 2 & 6 & 5 & 5 & 2 & 3 \\
\hline $\operatorname{Kim}[12]$ & 5 & 3 & 3 & 0 & 2 & 5 & 5 & 0 & 0 \\
\hline Chen [13] & 11 & 11 & 11 & 3 & 9 & 7 & 9 & 1 & 1 \\
\hline $\begin{array}{l}\text { Alexopoulos } \\
\text { [14] }\end{array}$ & 1 & 0 & 0 & 0 & 0 & 0 & 0 & 0 & 0 \\
\hline Jarius [15] & 1 & 0 & 0 & 0 & 0 & 0 & 1 & 0 & 1 \\
\hline Mimbrera [16] & 1 & 0 & 0 & 0 & 1 & 1 & 1 & 1 & 1 \\
\hline $\begin{array}{l}\text { Illustrative } \\
\text { case }\end{array}$ & 1 & 1 & 1 & 1 & 1 & 1 & 0 & 1 & 1 \\
\hline Total: & 94 & 83 & & 15 & 72 & $58(n=76)$ & $41(n=74)$ & 14 & 14 \\
\hline Percentage: & & $88.30 \%$ & & $16.00 \%$ & $76.80 \%$ & $76.30 \%$ & $55.40 \%$ & $14.90 \%$ & $14.90 \%$ \\
\hline
\end{tabular}

ND - no data

\section{Electrophysiologic studies}

EEG was documented for 66 patients, and $57.6 \%(38 / 66)$ had either temporal lobe seizures, interictal epileptiform abnormalities, or focal temporal slowing.

\section{Oncologic association}

Neoplasm was detected in $49.5 \%(46 / 93)$ of cases, with $91.3 \%(42 / 46)$ of the neoplastic cases being small cell lung cancer. There were three patients assumed to be SCLC based on a diagnosis of lung cancer and a clinical history that did not have a final pathologic confirmation [6]. Additional associated neoplasms reported include: one neuroendocrine tumour [3], one carcinoid of the thymus [4] one type B1 thymoma [14], and one melanoma [15]. The patient with type B1 thymoma had associated anti-Hu and anti-CV2 antibodies, and the patient with melanoma had associated Glutamic Acid Decarboxilase (GAD-65) antibodies, whereas the patients with associated neuroendocrine tumour and carcinoid of the thymus had no reported additional antibodies. The youngest patient with reported SCLC was a 42 year-old female [19]. The most commonly reported autoantibodies associated with $\mathrm{GABA}_{\mathrm{B}}-\mathrm{R}$ autoimmune disease were anti-Hu (10.8\%, 9/83), anti-SOX1 (10.8\%, 9/83), anti-GAD65 (8.5\%, 8/94), and $\mathrm{N}$-type voltage gated calcium antibodies $(4.8 \%, 4 / 83)$. Isolated cases with associated voltage-gated potassium channel, BR serine/threonine-protein kinase 2, NMDA-R, and CV2 autoantibodies have also been described.

\section{Treatment outcome}

Outcomes demonstrate a robust response to either immunotherapy or a combination of immunotherapy and cancer treatment when appropriate, with $86.3 \%(63 / 73)$ of patients treated either demonstrating partial or complete recovery. Of those treated with immunosuppressive agents, 34.2\% (25/73) of patients demonstrated a complete response, as defined by a return to a prior baseline or modified Rankin scale of $0-1$, depending on the metric used.

The most common immunosuppressive agents utilised were corticosteroids, IVIg, plasmapheresis, and steroid sparing agents. Tables $3 \mathrm{~A}$ and $3 \mathrm{~B}$ summarise treatment types and responses. Outcomes in patients without immunotherapy and/or cancer treatment were poor, with 6 out of $9(66.7 \%)$ dying. Interestingly, the two reported by Guan to have survived without immunotherapy and/or cancer treatment were treated with AEDs [6]. However, exact time to follow-up for these patients was not available, beyond that it was at least one month. Of the four patients treated with only AEDs, one demonstrated complete recovery, one demonstrated partial improvement, one remained stable without improvement, and the remaining one died. Due to the high mortality of SCLC, control of the underlying neoplasm was often the long-term limiting factor in patients with SCLC.

\section{Illustrative case}

In 2003, we encountered an 84 year-old gentleman with a history of heavy cigarette smoking, alcohol abuse, and atrial 
Table 3 A. Treatment responses in patients treated with immunosuppression, AED, or no treatment. One unidentified patient was treated with chemotherapy

$\begin{array}{lcccc} & \text { Patients Treated } & \text { Full Recovery } & \text { Partial Recovery } & \text { No Response } \\ \text { Steroids } & 16 & 9(56.2 \%) & 7(43.8 \%) & 0 \\ \text { Ivlg } & 15 & 6(40 \%) & 6(40 \%) & 3(20 \%) \\ \text { Steroids + IVIG' } & 13 & 5(33.5 \%) & 7(53.8 \%) & 1(7.7 \%) \\ \text { Steroids + PLEX } & 5 & 1(20 \%) & 2(40 \%) & 2(40 \%) \\ \text { Steroids+IVIG+PLEX } & 2 & 0 & 2 & 0 \\ \text { Steroid Sparing Agent + Corticoste- } & 3 & 1 & 1 & 1 \\ \text { roid } & 5 & 0 & 4(20 \%) \\ \text { Steroid Sparing Agent + IVIG or PLEX } & 5 & & 1 & 2 \\ \pm \text { Steroids } & 4 & 1 & 0 & 6 \\ \text { AED Only } & 6 & 0 & 30 & 16 \\ \text { No Treatment } & 69 & 23 & 43.5 \% & 23.2 \% \\ \text { Total: } & & 33.3 \% & & \end{array}$

Table 3 B. Treatment responses in patients treated with chemotherapy or combined chemotherapy and immunosuppression. All patients in this category had confirmed neoplasm. Some patients had additional radiotherapy

\begin{tabular}{lcccc} 
& Patients Treated & Full Recovery & Partial Recovery & No Response \\
\hline Chemo only & 6 & 0 & 4 & 2 \\
Chemo + corticosteroids & 1 & 1 & 0 & 0 \\
Chemo + IVIG & 2 & 1 & 1 & 0 \\
Chemo + Steroids + IVIG & 9 & 1 & 6 & 2 \\
Corticosteroids + IVIG \pm PLEX+Chemo & 1 & 0 & 1 & 0 \\
Chemo + Steroid Sparing Agent + Ste- & 1 & 0 & 1 & 0 \\
roids + Chemo & & & & 4 \\
Total: & 20 & 3 & $65 \%$ & $20 \%$ \\
Percentage: & & $15 \%$ &
\end{tabular}

fibrillation who presented due to an unwitnessed presumed first generalised seizure with associated cognitive decline and ataxia with subacute gait instability. His initial neurologic examination was notable for intact cognition, reduced left hemibody light touch, left greater than right heel to shin ataxia, left greater than right finger to nose dysmetria, and gait ataxia.

On day 12 , repeat brain MRI was performed with and without demonstrated right mesial temporal lobe hyperintensity on T2 imaging with increased restricted diffusion of the right mesial temporal lobe, insula, and adjacent basal ganglia (Fig. 1). Lumbar puncture was performed, with CSF laboratory values of: < 1 WBC, 20 RBC, normal glucose, protein 70, NSE elevated 31.6, and two oligoclonal bands. CSF infectious studies were all negative, including: HSV PCR, fungal studies, AFB culture, viral culture, Cryptococcus Ag, EBV, and West Nile Ag.

The patient experienced rapidly progressive cognitive decline with a parallel worsening seizure course, with obtundation and non-convulsive status epilepticus NCSE within
21 days (Fig. 2), followed by death. Seizures arose from the right hemisphere and were refractory to phenytoin with partial EEG response to high dose fosphenytoin and valproate combination therapy. Fine needle aspirate of a pulmonary mass was positive for SCLC.

This patient's case was reviewed retrospectively in 2018, and it was proposed that $\mathrm{GABA}_{\mathrm{B}}-\mathrm{R}$ autoimmune encephalitis was the most likely cause of death based on the patient's clinical characteristics of ataxia with seizures progressing to status epilepticus [4] imaging profile consistent with limbic encephalitis, small-cell lung cancer association [5] and CSF without pleocytosis [4]. Laboratory testing of stored patient's serum and CSF by cell based assays were both positive for $\mathrm{GABA}_{\mathrm{B}}-\mathrm{R}$ antibodies, confirming the diagnosis 15 years later.

\section{Clinical implications}

The number of identified cases of $\mathrm{GABA}_{B}-\mathrm{R}$ antibody autoimmunity available for review has expanded in the literature 


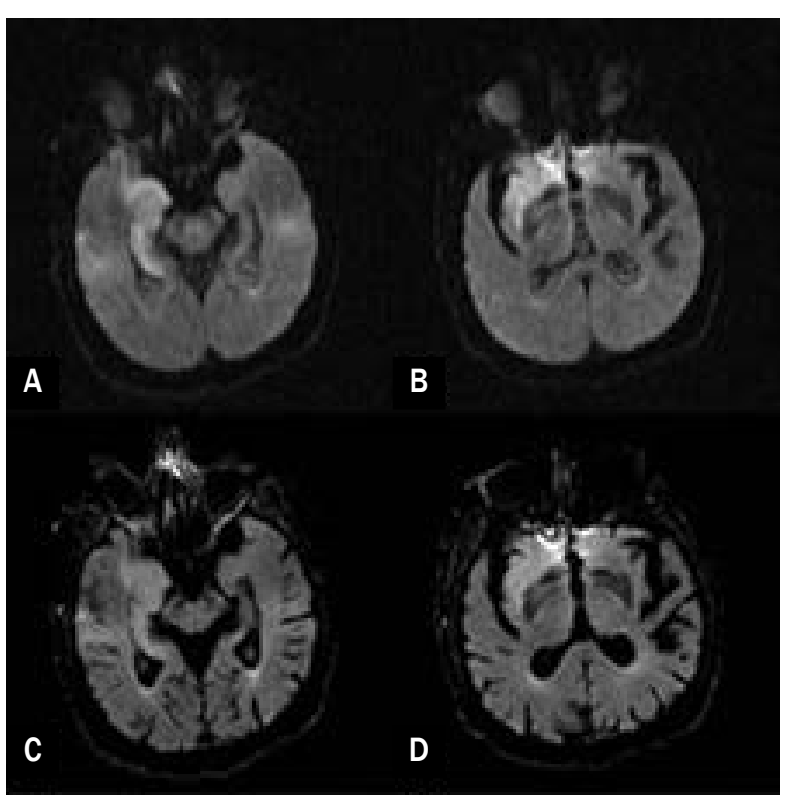

Figure 1. Brain MRI DWI sequence with restricted diffusion of the right mesial temporal lobe, insula, and basal ganglia $(A, B)$ and corresponding brain MRI T2 hyperintensity (C,D) since the original description in 2010. As a result, a distinctive clinical syndrome has become increasingly solidified, characterised by the cardinal features of refractory seizures or status epilepticus and frequent SCLC association. This review demonstrates that the disease is more common in males than in females, that bilateral temporal lobe hyperintensity is a very frequent radiographic finding, that a substantial minority have noninflammatory CSF, and that ataxia is more frequent in these patients than most physicians had previously appreciated. The included data from Asian countries reveals that $\mathrm{GABA}_{B}-\mathrm{R}$ autoimmunity is probably not bound by race or ethnicity and most likely has a similar clinical syndrome worldwide, as the frequency of SCLC is high. The study also highlights that other associated neoplasms besides SCLC may be present in a small group of patients, suggesting that a comprehensive oncologic evaluation is warranted.

While features of $\mathrm{GABA}_{\mathrm{B}}-\mathrm{R} \mathrm{Ab}$ mediated autoimmune disease can overlap with other common autoimmune diseases of the central nervous system (CNS), $\mathrm{GABA}_{\mathrm{B}}-\mathrm{R}$ autoimmunity should be suspected over NMDA-R encephalitis in individuals with older average age of onset, with the average of onset being 59 years versus 21 respectively [20]. $\mathrm{GABA}_{B}-\mathrm{R}$

Fpl-F7

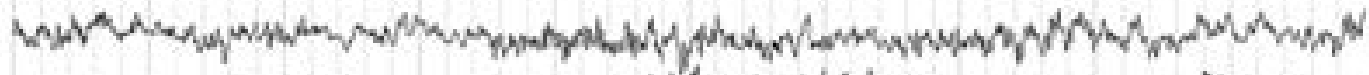

F7-T3

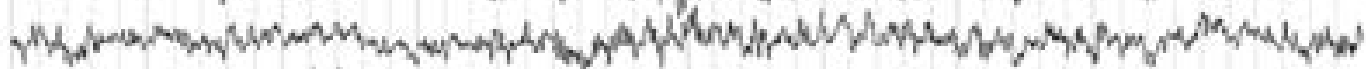

T3-T5

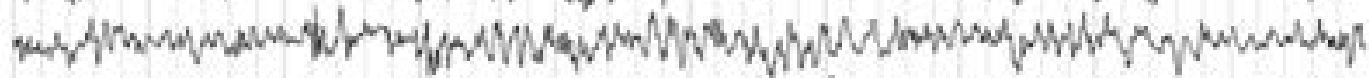

T5.01

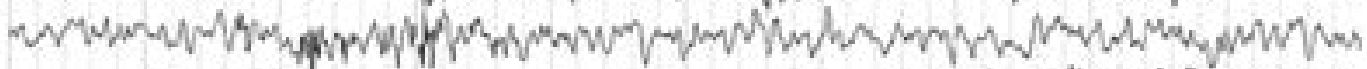

Fpl-F3

F3-C3

C3-P3

P3-O1

Fp2-F4

$\mathrm{F} 4 \cdot \mathrm{C} 4$

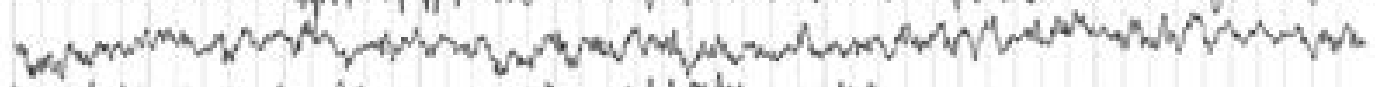

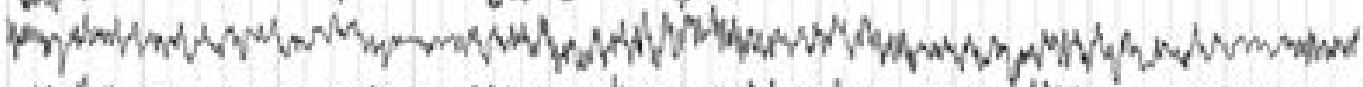

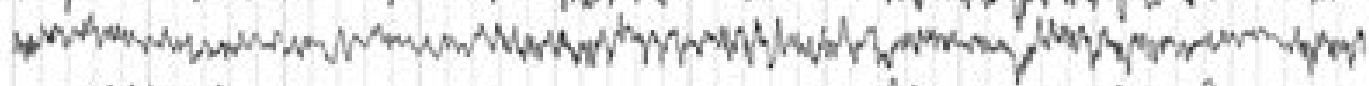

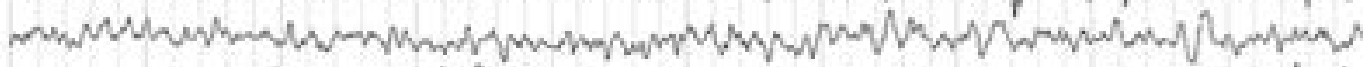

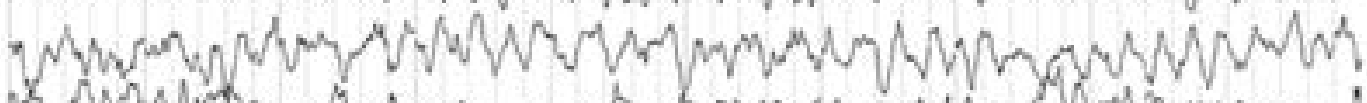

C4-P4

$\mathrm{P} 4-02$

Fp2-F8

F8-T4

T4-T6

T6.02

•EKG-A2

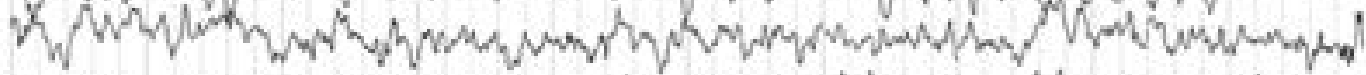

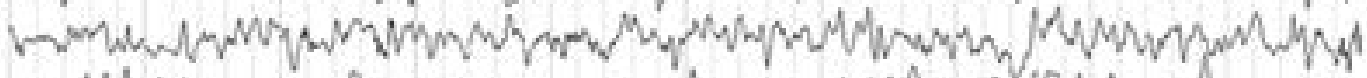

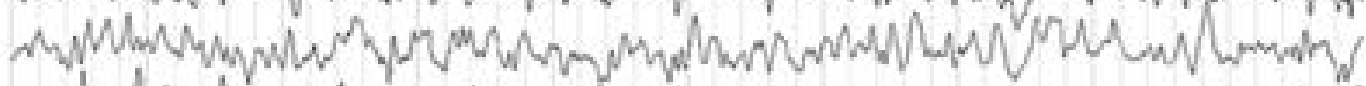

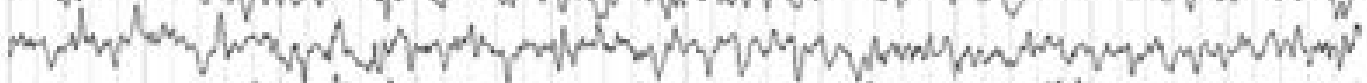

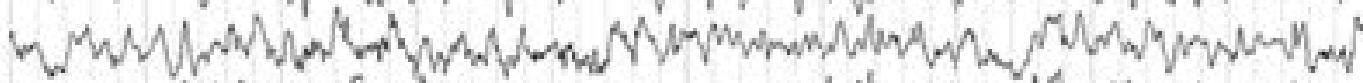

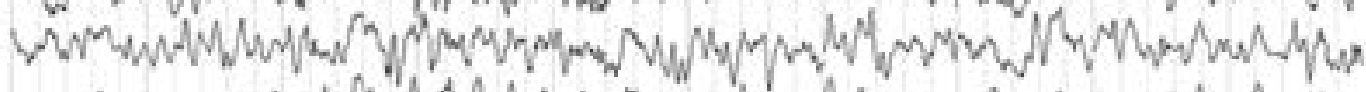

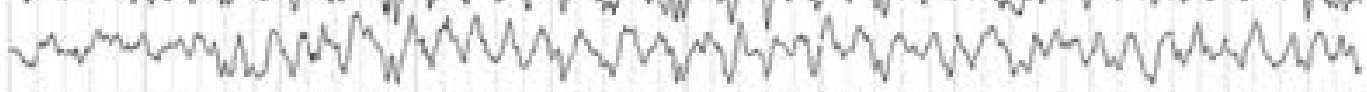

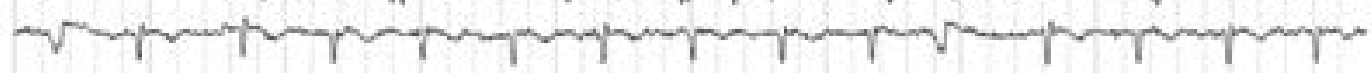

Figure 2. EEG demonstrating non-convulsive status epilepticus, with right hemisphere predominance 
autoimmunity is also more common in males $(2: 1)$, whereas NMDA-R autoimmune encephalitis is female predominant (8:1). Additionally, $\mathrm{GABA}_{\mathrm{B}}-\mathrm{R}$ autoimmunity is more likely to present with seizures or associated ataxia and has different oncologic associations (SCLC versus ovarian teratoma) compared to NMDA-R autoimmune encephalitis [21]. While anti-Hu autoantibodies are commonly seen in association with SCLC, with a similar average age of onset (63 years) as $\mathrm{GABA}_{\mathrm{B}}-\mathrm{R}$ autoimmunity, it is much more likely to present with paraneoplastic peripheral neuropathy than seizure or limbic encephalitis [22]. In cases of isolated ataxia in association with SCLC, anti-Hu and anti-GABA $-\mathrm{R}$ antibodies should be strongly considered in the differential.

The recognition of $\mathrm{GABA}_{B}-\mathrm{R}$ autoimmunity has important clinical implications for patient outcomes, as untreated patients are more likely to die or progress to coma. The recognition that CSF can be non-inflammatory is important, as CSF pleocytosis is often used as a clinical justification for empiric treatment of suspected autoimmune neurological disorders while waiting for autoantibody testing results. Additionally, it has been recently reported that patients with antibodies targeting cell surface proteins can often have a non-inflammatory CSF [23]. The retrospective diagnosis in our patient deceased 15 years earlier was made possible by the subsequent discovery and characterisation of the clinical, imaging, and laboratory findings of $\mathrm{GABA}_{\mathrm{B}}-\mathrm{R}$ autoimmune encephalitis.

Aggressive treatment with immunosuppression is warranted in the event of suspected $\mathrm{GABA}_{B}-\mathrm{R}$ autoimmune encephalitis, given the high potential for improvement, and the deleterious outcomes in patients who are not treated. None of the untreated patients in the literature have recovered spontaneously. The available data on treatment and response is likely influenced by the tendency to treat more responsive cases with corticosteroid agents alone, and then subsequently add further treatments to the regimen for refractory cases. Patients treated with corticosteroids alone versus IVIg alone did show a more robust treatment response on average (56.2\% vs $40 \%$ complete recovery). However, given the small number of patients, the lack of randomisation, and the retrospective data collection, no definitive conclusions as to the superiority of different immunosuppressive agents can be drawn. Treatment with a combination of chemotherapy and immunosuppression probably implied a poorer oncologic picture, so it is not surprising that response rates were not as favourable in this group. The five-year survival rate of SCLC is less than $10 \%$ [24] which ultimately will limit the life expectancy in patients found to have associated SCLC, but immunosuppressive therapies can still often lead to improvement in symptoms attributable to $\mathrm{GABA}_{\mathrm{B}}-\mathrm{R}$ autoimmune encephalitis.

Clinicians should consider a diagnosis of $\mathrm{GABA}_{B}-\mathrm{R}$ autoimmune encephalitis in patients with new onset refractory seizures with associated SCLC with or without ataxia, even in the absence of CSF pleocytosis. It would be best to assess both serum and CSF samples, but CSF has the higher yield of detection based on available data. In adult patients with suspected or confirmed $\mathrm{GABA}_{\mathrm{B}}$ - $\mathrm{R}$ autoimmune encephalitis, an initial chest CT to screen for SCLC is appropriate [25]. However, if chest CT is negative with positive serum or CSF $\mathrm{GABA}_{B}-\mathrm{R}$ antibodies, whole body PET-scan is indicated, as this has been demonstrated to be superior to CT alone when screening for occult neoplasm in the setting of paraneoplastic antibodies [25, 26]. While the youngest patient on record with associated SCLC was 42 years of age, it is reasonable to screen younger adults found to have $\mathrm{GABA}_{\mathrm{B}}-\mathrm{R}$ antibodies, given the high oncologic association, close to $50 \%$. If a neoplasm is discovered, oncology consultation should be sought so that appropriate oncological therapies can be administered [22,27]. In the event that a neoplasm is not identified on initial screening, we recommend following the screening guidelines drawn up by the European Federation of Neurological Societies [25].

\section{Future directions}

An area for potential future study could be assessing the effectiveness of different types of AEDs in cases of $\mathrm{GABA}_{B}$ $-R$ associated epilepsy, particularly those cases with status epilepticus. Further long-term cognitive outcome follow-up data is also needed. Additionally, as more cases are reported, the understanding of the epidemiology and clinical characteristics of $\mathrm{GABA}_{\mathrm{B}}-\mathrm{R}$ autoimmunity will continue to increase.

Ethical approval was not necessary for preparation of this article.

This publication was prepared without any external sources of funding.

\section{References:}

1. Dalmau J, Tüzün E, Wu Hy, et al. Paraneoplastic anti-N-methyl-D-aspartate receptor encephalitis associated with ovarian teratoma. Ann Neurol. 2007; 61(1): 25-36, doi: 10.1002/ana.21050, indexed in Pubmed: 17262855.

2. Gable MS, Sheriff H, Dalmau J, et al. The frequency of autoimmune N-methyl-D-aspartate receptor encephalitis surpasses that of individual viral etiologies in young individuals enrolled in the California Encephalitis Project. Clin Infect Dis. 2012; 54(7): 899-904, doi: 10.1093/cid/ cir1038, indexed in Pubmed: 22281844.

3. Lancaster E, Lai M, Peng X, et al. Antibodies to the GABAB receptor in limbic encephalitis with seizures: case series and characterisation of the antigen. The Lancet Neurology. 2010; 9(1): 67-76, doi: 10.1016/ s1474-4422(09)70324-2.

4. Boronat A, Sabater L, Saiz A, et al. GABA(B) receptor antibodies in limbic encephalitis and anti-GAD-associated neurologic disorders. Neurology. 2011; 76(9): 795-800, doi: 10.1212/WNL.0b013e31820e7b8d, indexed in Pubmed: 21357831.

5. Höftberger R, Titulaer MJ, Sabater L, et al. Encephalitis and GA$B A B$ receptor antibodies: novel findings in a new case series of 20 patients. Neurology. 2013; 81(17): 1500-1506, doi: 10.1212/ WNL.0b013e3182a9585f, indexed in Pubmed: 24068784.

6. Guan $\mathrm{HZ}$, Ren $\mathrm{HT}$, Yang XZ, et al. Limbic Encephalitis Associated with Anti-y-aminobutyric Acid B Receptor Antibodies: A Case Series 
from China. Chin Med J (Engl). 2015; 128(22): 3023-3028, doi: 10.4103/0366-6999.168989, indexed in Pubmed: 26608981.

7. Onugoren MD, Deuretzbacher D, Haensch CA, et al. Limbic encephalitis due to GABABand AMPA receptor antibodies: a case series. Journal of Neurology, Neurosurgery \& Psychiatry. 2014; 86(9): 965-972, doi: 10.1136/jnnp-2014-308814.

8. Benarroch EE. GABAB receptors: structure, functions, and clinical implications. Neurology. 2012; 78(8): 578-584, doi: 10.1212/ WNL.0b013e318247cd03, indexed in Pubmed: 22351795.

9. Fritschy JM, Meskenaite V, Weinmann 0 , et al. GABAB-receptor splice variants GB1a and GB1b in rat brain: developmental regulation, cellular distribution and extrasynaptic localization. Eur J Neurosci. 1999; 11(3): 761-768, indexed in Pubmed: 10103070.

10. Schuler V, Lüscher C, Blanchet C, et al. Epilepsy, hyperalgesia, impaired memory, and loss of pre- and postsynaptic GABA(B) responses in mice lacking $G A B A(B(1))$. Neuron. 2001; 31(1): 47-58, indexed in Pubmed: 11498050.

11. Dalmau J, Geis C, Graus F. Autoantibodies to Synaptic Receptors and Neuronal Cell Surface Proteins in Autoimmune Diseases of the Central Nervous System. Physiological Reviews. 2017; 97(2): 839-887, doi: 10.1152/physrev.00010.2016.

12. Kim TJ, Lee ST, Shin JW, et al. Clinical manifestations and outcomes of the treatment of patients with GABAB encephalitis. J Neuroimmunol. 2014; 270(1-2): 45-50, doi: 10.1016/j.jneuroim.2014.02.011, indexed in Pubmed: 24662003.

13. Chen X, Liu F, Li JM, et al. Encephalitis with antibodies against the GABAB receptor: seizures as the most common presentation at admission. Neurological Research. 2017; 39(11): 973-980, doi: 10.1080/01616412.2017.1351062.

14. Alexopoulos H, Dagklis IE, Akrivou S, et al. Autoimmune encephalitis with GABAB antibodies, thymoma, and GABAB receptor thymic expression. Neurol Neuroimmunol Neuroinflamm. 2014; 1(4): e39, doi: 10.1212/NXI.0000000000000039, indexed in Pubmed: 25364773.

15. Jarius $\mathrm{S}$, Steinmeyer F, Knobel A, et al. GABAB receptor antibodies in paraneoplastic cerebellar ataxia. J Neuroimmunol. 2013; 256(1-2): 94-96, doi: 10.1016/j.jneuroim.2012.12.006, indexed in Pubmed: 23332614.

16. DeFelipe-Mimbrera A, Masjuan J, Corral Í, et al. Opsoclonus-myoclonus syndrome and limbic encephalitis associated with GABAB receptor antibodies in CSF. J Neuroimmunol. 2014; 272(1-2): 91-93, doi: 10.1016/j.jneuroim.2014.04.009, indexed in Pubmed: 24814391.

17. Wells EM, Dalmau J. Paraneoplastic neurologic disorders in children. Curr Neurol Neurosci Rep. 2011; 11(2): 187-194, doi: 10.1007/ s11910-010-0169-4, indexed in Pubmed: 21161703.
18. Kruer MC, Hoeftberger R, Lim KY, et al. Aggressive course in encephalitis with opsoclonus, ataxia, chorea, and seizures: the first pediatric case of $y$-aminobutyric acid type $B$ receptor autoimmunity. JAMA Neurol. 2014; 71(5): 620-623, doi: 10.1001/jamaneurol.2013.4786, indexed in Pubmed: 24590315.

19. Chen X, Liu F, Li JM, et al. Encephalitis with antibodies against the GABA receptor: seizures as the most common presentation at admission. Neurol Res. 2017; 39(11): 973-980, doi: 10.1080/01616412.2017.1351062, indexed in Pubmed: 28974152.

20. Titulaer MJ, McCracken L, Gabilondo I, et al. Treatment and prognostic factors for long-term outcome in patients with anti-NMDA receptor encephalitis: an observational cohort study. Lancet Neurol. 2013; 12(2): 157-165, doi: 10.1016/S1474-4422(12)70310-1, indexed in Pubmed: 23290630.

21. Dalmau J, Gleichman AJ, Hughes EG, et al. Anti-NMDA-receptor encephalitis: case series and analysis of the effects of antibodies. Lancet Neurol. 2008; 7(12): 1091-1098, doi: 10.1016/S14744422(08)70224-2, indexed in Pubmed: 18851928.

22. Graus F. Anti-Hu-associated paraneoplastic encephalomyelitis: analysis of 200 patients. Brain. 2001; 124(6): 1138-1148, doi: 10.1093/ brain/124.6.1138.

23. Escudero D, Guasp M, Ariño H, et al. Antibody-associated CNS syndromes without signs of inflammation in the elderly. Neurology. 2017; 89(14): 1471-1475, doi: 10.1212/WNL.0000000000004541, indexed in Pubmed: 28878050.

24. Kalemkerian GP. Small Cell Lung Cancer. Semin Respir Crit Care Med. 2016; 37(5): 783-796, doi: 10.1055/s-0036-1592116, indexed in Pubmed: 27732999.

25. Titulaer MJ, Soffietti R, Dalmau J, et al. European Federation of Neurological Societies. Screening for tumours in paraneoplastic syndromes: report of an EFNS task force. Eur J Neurol. 2011; 18(1): 19e3, doi: 10.1111/j.1468-1331.2010.03220.x, indexed in Pubmed: 20880069.

26. McKeon A, Apiwattanakul M, Lachance DH, et al. Positron emission tomography-computed tomography in paraneoplastic neurologic disorders: systematic analysis and review. Arch Neurol. 2010; 67(3): 322-329, doi: 10.1001/archneurol.2009.336, indexed in Pubmed: 20065123.

27. Mundiyanapurath $\mathrm{S}$, Jarius $\mathrm{S}$, Probst $\mathrm{C}$, et al. GABA-B-receptor antibodies in paraneoplastic brainstem encephalitis. J Neuroimmunol. 2013; 259(1-2): 88-91, doi: 10.1016/j.jneuroim.2013.04.004, indexed in Pubmed: 23628208. 